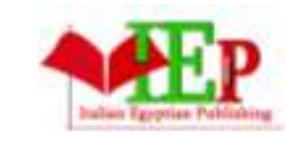

ISSN: 2735-4342
INTERNATIONAL JOURNAL OF

MULTIDISCIPLINARY STUDIES IN ART AND

TECHNOLOGY

VOLUME 2, ISSUE 2, 2019, 29-47.

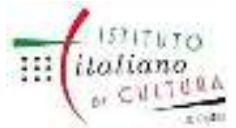

www.egyptfuture.org/ojs/

\title{
THE INTERACTION BETWEEN MATERIALS TECHNOLOGY AND THEATRICAL SCENOGRAPHY
}

\author{
Aya Mohamed Kamal EIDean Amean \\ Lecturer -Faculty of fine arts at Alexandria University \\ ayaMohamed.Kamal@alexu.edu.eg
}

\begin{abstract}
:
The ability of modern technology to connect the elements of scenography and materials technology leads to a growing link between theatrical possibilities and theatrical audience through the ability to reshape theatrical elements in the most basic components, and with all the new moves comes a new wave of talk about what the new technology To connect with the audience, by connecting theater experiences and theatrical audience with raw materials and creating scenes capable of movement and interaction between the movement of the audience, lighting, the movement of actors and sound, with the ability to change, form and grow, have the ability to predict the act and Reaction.

And by searching beyond the materials and properties that can be converted and adapted to transform the material from materials unable to react to materials that can be transformed and formed on their own technology was able to employ chemical transformations of materials and control their reactions and directed to become specific characteristics to exceed The research and theatrical studies, which conducted two-way research, either theatrical design or the techniques and technological capabilities exploited in the design and neglected the search for the modern materials that have been exploited to implement these designs.
\end{abstract}

\section{Introduction:}

If we want to control the mechanical movement of materials, there must be an influence and stimulus for this movement within a general design in which all the elements interact with each other, so the change in shape is the result of a series of movements within a kinetic system in which the design deals with its elements so that the view depends on the relationship between these elements, Movement includes every interaction, transition, and change in color or shape, which generates more change and continuity. It operates within a specific mechanism or by reconfiguring it without replacing its place through changes in the lighting systems.

\section{Research problem}

do Modern materials have the ability to achieve human requirements and needs in various fields, how can we find alternatives and appropriate solutions to increase their interaction to serve 


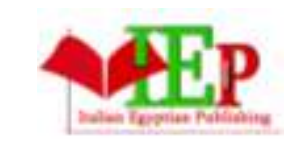

ISSN: $2735-4342$
INTERNATIONAL JOURNAL OF

MULTIDISCIPLINARY STUDIES IN ART AND

TECHNOLOGY

VOLUME 2, ISSUE 2, 2019, 29-47.

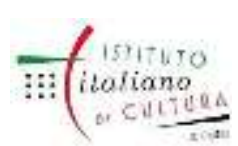

www.egyptfuture.org/ojs/

humans, either in architecture or design, and do modern materials have the ability to interact and self-movement and have the effective role in the design process

\section{$\underline{\text { Research Objective }}$}

Clarify the nature of the relationship between materials and their ability to make a change in thought and design.

\section{Research methodology}

An analytical survey study that depends on monitoring and analyzing the extent of technological progress and its confirmation of the idea.

\section{Research procedures}

The search strategy is based on two directions:

The first direction: the research behind the exploitation of materials in a way that was not used before to achieve a scenography in which theatrical architecture is intertwined with the scenic elements.

The second direction: the research behind sustainability and re-exploitation of materials related to theatrical scenography and the role of modern technologies in the exploitation of raw materials in various fields and the influential role played by raw materials technology to reach the maximum possible benefit while preserving the environment, either through the use of non-harmful materials or raw materials recyclable.

The material is the basic element in the design, and when starting to implement it, we must carefully choose the space prepared for it, the moving parts and the consequences of the movement and how the materials are used, either by creating new materials that have properties that differ from the materials in their normal form or re-employing the old materials and Which were not intended for these uses in a different way, (flexible materials that reshape themselves by changing the surrounding conditions, old materials that rebuild their particles to provide rigidity, adaptive materials that deal with the size of the theatrical space) and knowing the relationship between materials and their ability to make a change in design thought And exploring the aspects related to the development of materials and making them capable of transformation, and alteration, to include movement every interaction, transition, or change in color or shape, which generates more change, and continuity in changing, which may be gradual or sudden, in the form or in the internal components. Or even in the technological capabilities of these materials, which is one of the most important basic factors in determining the extent to which modern materials are used or not in the sciences of materials and raw materials, which expresses the link between the use of raw materials 


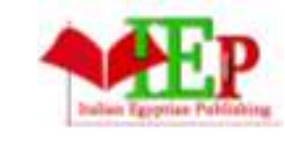

ISSN: $2735-4342$
INTERNATIONAL JOURNAL OF

MULTIDISCIPLINARY STUDIES IN ART AND

TECHNOLOGY

VOLUME 2, ISSUE 2, 2019, 29-47.

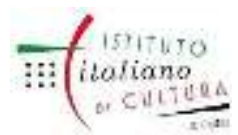

www.egyptfuture.org/ojs/

and its concepts. It is beneficial and technical, and through the human vision of his emerging needs and the emergence of calls for sustainable development and preservation of the environment and the relationship of all this with theatrical arts.

\section{Materials Perspective movements:}

When a series of perspective transformations of matter occurs (either by reflecting the light or changing into different shapes or by changing its shape as a result of a change in the surrounding temperature or other changes as a result of the chemical composition of the materials) it mixes the kinetic mechanism of the elements with advanced technological techniques. They have become movable and changeable and have the ability to form with one or separate movements, meaning that each part is responsible for its movement, or the movement may be through design.

The design is done through the mechanics of the movement of the materials when the shapes derive their form from nature or depending on their natural movement. In organizing design elements and exploring the values of mobile beauty based on the designer's creative ability to look forward to new aesthetic values represented by creating changing forms characterized by their mobility, which has always been fixed.

The modern age has allowed us to transform fixed data into design solutions, and perhaps the loss of human cultural identity in the modern age and his attempt to adapt is what allowed creating advanced design solutions for theatrical scenography to play a major role by trying to understand the principles behind those solutions and Creating new solutions that contain inspiring creative qualities through the symbolic and advanced technological vision of the scenographical elements in the theatrical performances, so the importance of innovation in the design of theatrical performance and seeking for creating a sense of the environment within the exhibition spaces using advanced techniques and architectural designs is what drives the audience to re-examine the place Through which the stage of the fixed "place" can be transformed into a "space" or connected, moving entity capable of changing in a way that we can control.

And all the new technological moves have forced us to connect with audiences in new ways to bring the theater audience closer to the immersive theater by making more creative materials. From the younger generation of European theater designers indirectly by creating micro-architectural 


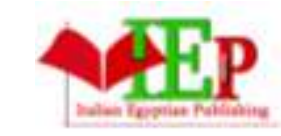

ISSN: $2735-4342$
INTERNATIONAL JOURNAL OF

MULTIDISCIPLINARY STUDIES IN ART AND

TECHNOLOGY

VOLUME 2, ISSUE 2, 2019, 29-47.

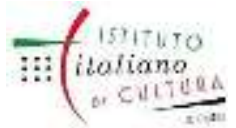

www.egyptfuture.org/ojs/

environments and figuratively, these spaces are inhabited by performers who make their own designs as objects and architecture with details made of real materials and projected images, and machine-like structures Designers such as Wilfred Minks, Achim Freyer, \& Erich Wonder, who

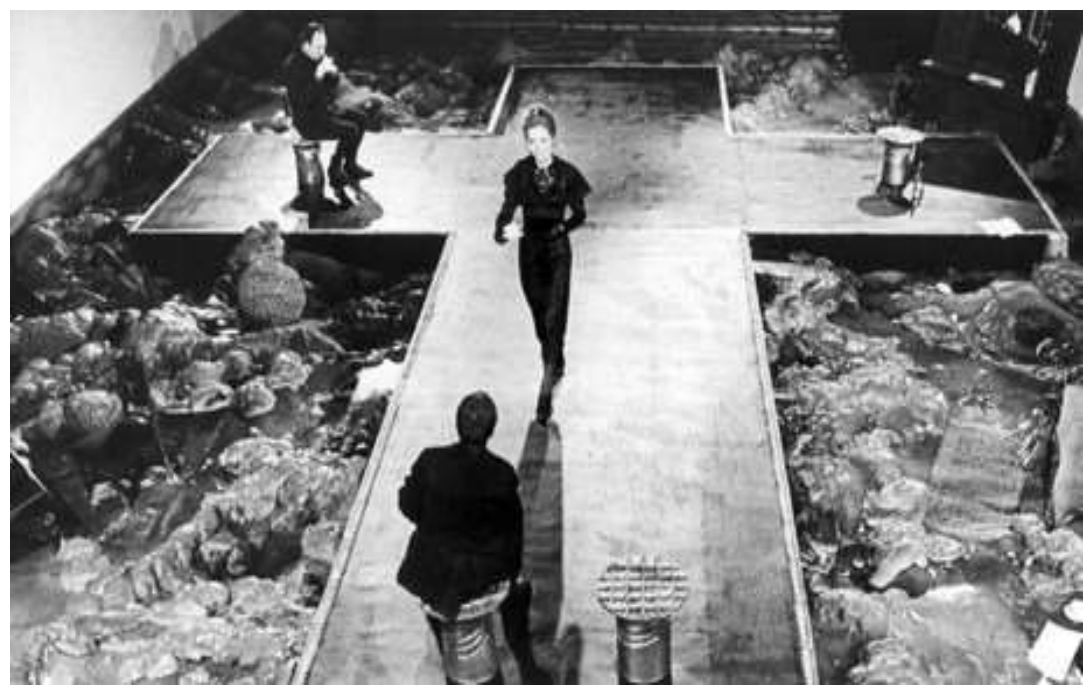
performed in the generously funded German state theaters, revived the tradition of German theater design that had reached its peak in the 1920s and formed partnerships with a string of enterprising theater directors such as Peter Stein, Klaus Michael Gruber \& Heiner Muller toward the making of what was called "theater spaces" or "theatrically organized spaces".

When German scene designers created their own visual language in presenting classical texts on Western theater, one of the first to raise theater design to a new level of attention was Wilfred Minks, who achieved fame and controversy with natural scenes by incorporating real materials such as artificial grass, sand, and water, plastic, metal, and light as architectural materials, which made it a point of development in the design of theatrical performances in the German theater.

Achim Freyer and Erich Wonder have provided unprecedented images between theatrical design and installation that are based on fusing visual images drawn from industrial and urban environments in Germany with inspiration from artists such as Kandinsky, Malevich, Mark Rothko \& Barnett Newman, to make Ideal theatrical environments look more like fantasy movie spaces than structures for eighteenth-century plays or operas.

The exploitation of the ideas of some materials used in the design that help in the formation of the dynamic theatrical scene and the possibility of using theatrical space based on the real terrain and architectural elements such as archaeological places or natural places or real materials such as metals, wood and mirrors and focusing on the psychological functional model of the place Theatrical through re-designing or re-arranging the space and exploiting new materials to explore the kinetic form and its ability in linking the design with the architectural composition of the theatrical environment to transform the static space into a mobile (a dynamic theatrical environment), which is what keeps the audience and performers in continuous movement. 


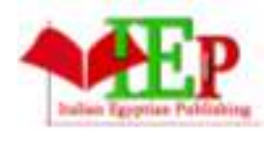

ISSN: $2735-4342$
INTERNATIONAL JOURNAL OF

MULTIDISCIPLINARY STUDIES IN ART AND

TECHNOLOGY

VOLUME 2, ISSUE 2, 2019, 29-47.

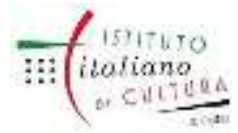

www.egyptfuture.org/ojs/

Some performances have relied on the use of modern and mechanical architecture for the stage as the main element, and it has been combined with lighting technology and light projection while relying on audience participation as one of the elements of scenography, in addition to the use of modern technology in lighting, projections, and screens as main elements of the scenography elements.

\section{Open are performance:}

And since the ideas of three-dimensional materials are one of the elements that help in the formation of the dynamic space, and the possibilities of using theatrical space as a real expression based on the use of real terrain or the combination of these structures and real elements and threedimensional light projections, making the theatrical view subject to formation and change, as happened in The opening ceremony of the Sochi Olympics 2014 , in which three-dimensional light projections were used and mixed with real materials such as structures and holographic elements, in addition to the projections on the performers themselves, so that the show turned into a mixture of moving and interacting elements, and the use of special color diversity was With lighting and even the costumes of the performers, and the combination of light projections on the elements made of real materials, gave the audience the ability to explore the kinetic form and its ability to change and change through modern visions of the overlapping materials and structures in the visual composition of the display environment through re-design or Arranging the space and exploiting new materials by transforming the static space into a moving one (a dynamic theatrical 
INTERNATIONAL JOURNAL OF

MULTIDISCIPLINARY STUDIES IN ART AND

TECHNOLOGY

environment) In which the audience and the performers remain in constant movement through the changing role of the performer, which allowed the dynamic behavior of the theatrical space. The

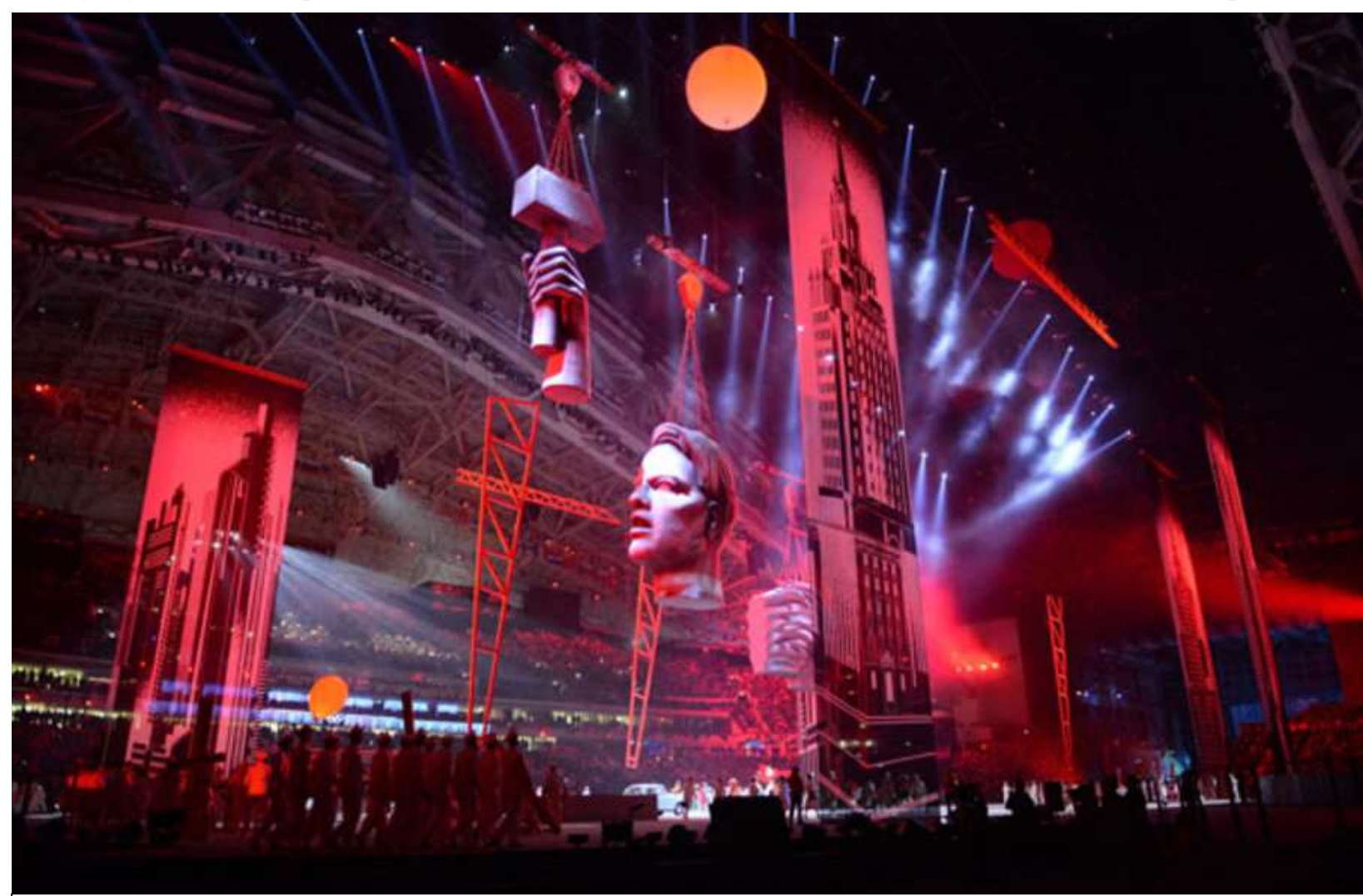

The opening ceremony of the 2014 Winter Olympics in Sochi, Russia, on 7 February.

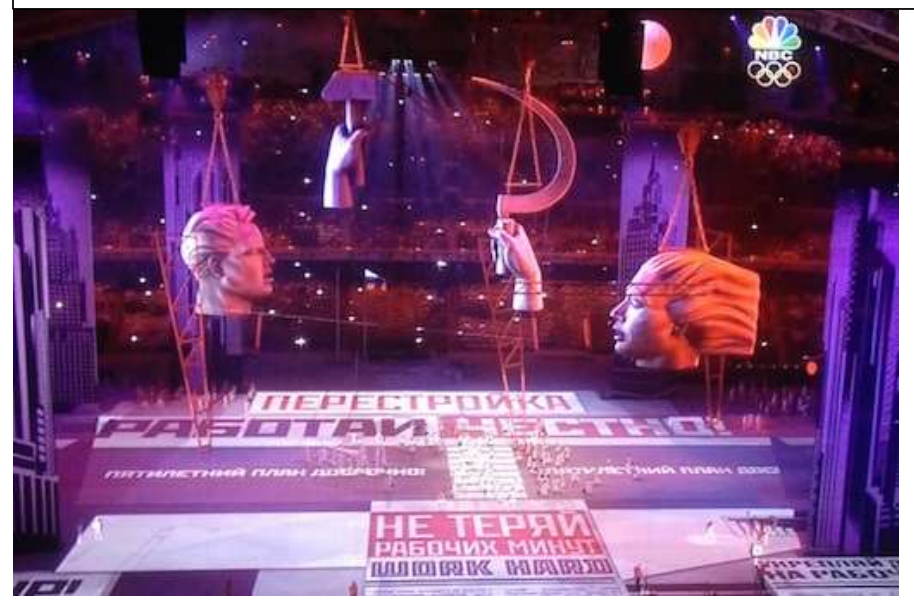

incorporation of scientific innovations was not only a means of assembling groups of technical devices and tricks but a tool for creating a multidisciplinary environment to present a theatrical environment that

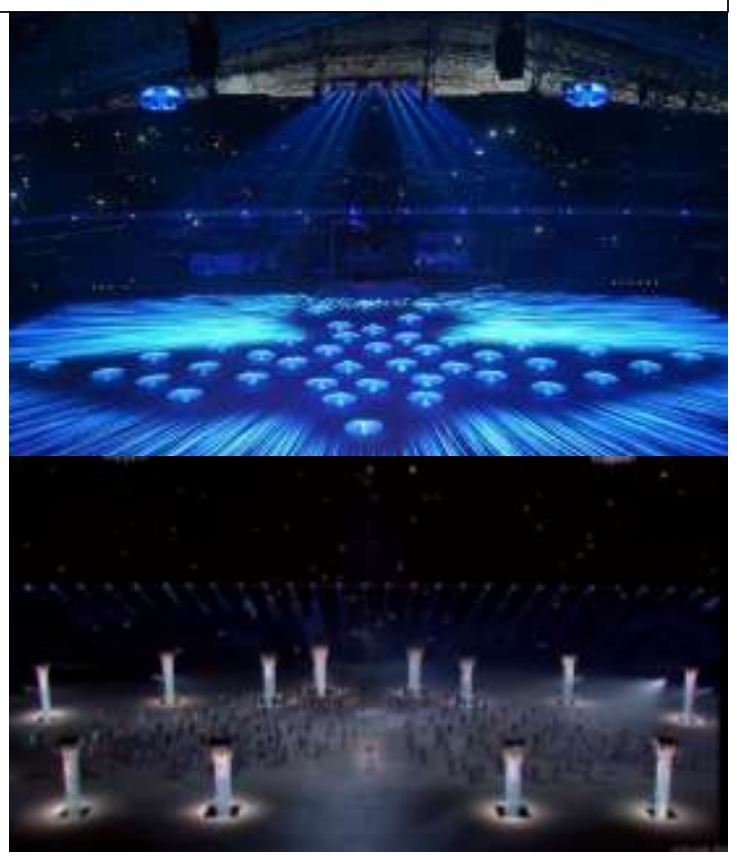




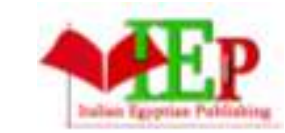

ISSN: $2735-4342$
INTERNATIONAL JOURNAL OF

MULTIDISCIPLINARY STUDIES IN ART AND

TECHNOLOGY

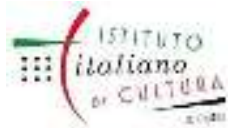

www.egyptfuture.org/ojs/

is subject to the formation and change with the latest systems Mechanical and able to accompany multiple scenographic settings through its focus on moving environments, and able to join each other to form a flexible space that can be transformed and modified in its qualities to compose the dramatic event beyond the visual scene design by developing animated scenes through hydraulic systems that create an impression of the environment Continuous development by integrating all technological means in theatrical performance, and exploiting front and rear projection techniques to create an attractive illusion by controlling the perspective of the moving image, which conveys the interaction between the elements using Infrared cameras sense the performers when they are on stage to associate with video projections that move to appear realistic. And by designing synthetic architectural works for theatrical performance, the interest of new media has shifted from the screen and the automated imaginary theater to the physical space.

Staged performance: Theatrical performance Amaluna 2012:

The show is a mysterious island, with an enchanted forest, and the most important feature is the carefully designed forests of bamboo-like branches that surround the frame and surround the turntable and the forests use retractable stairs in the scenes The view is made of steel and aluminum, the canopy that supports the display structure was a challenge due to its huge weight in addition to The lower structure (platform), which is also made of steel and aluminum,
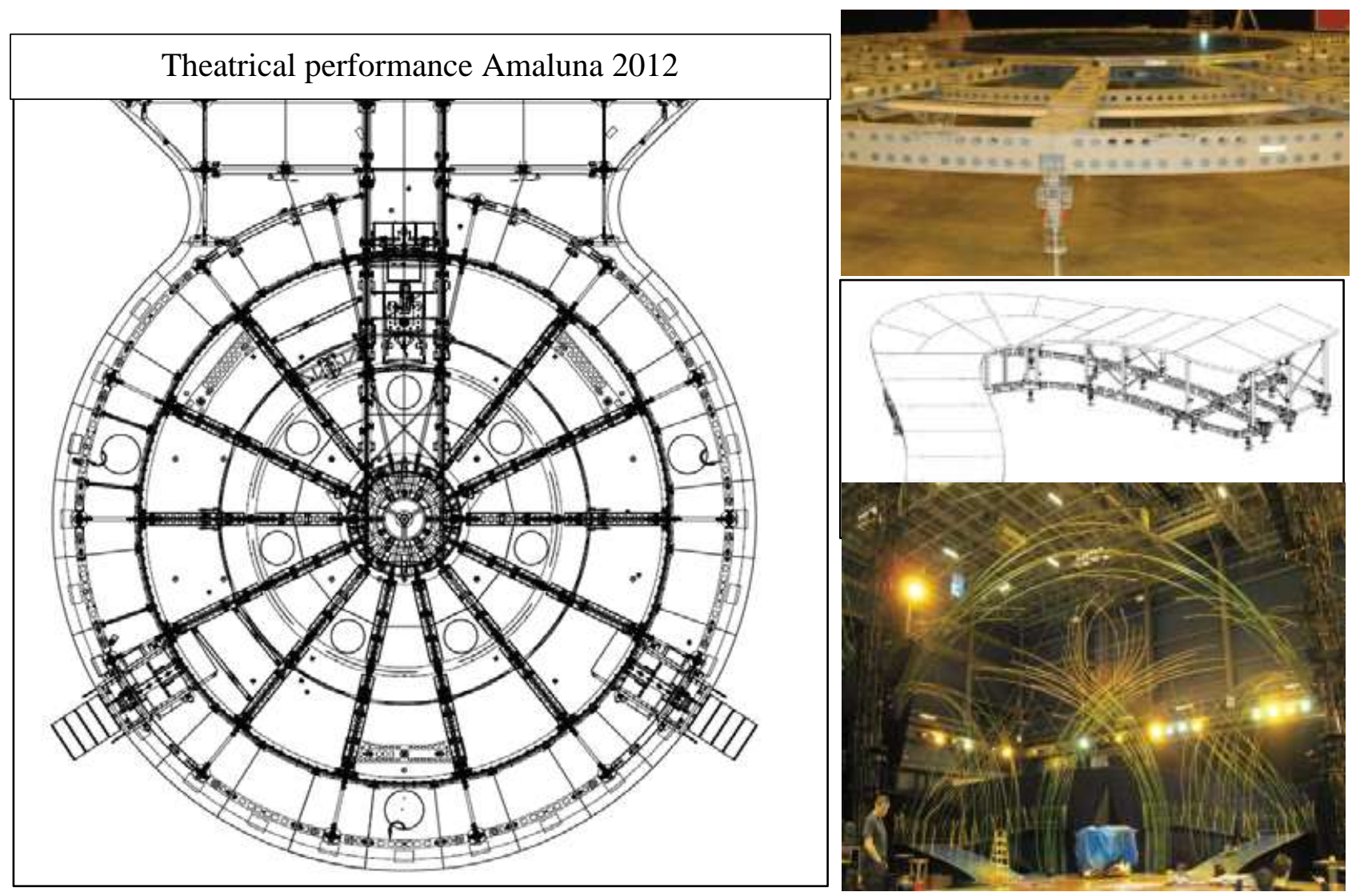
INTERNATIONAL JOURNAL OF

MULTIDISCIPLINARY STUDIES IN ART AND

TECHNOLOGY
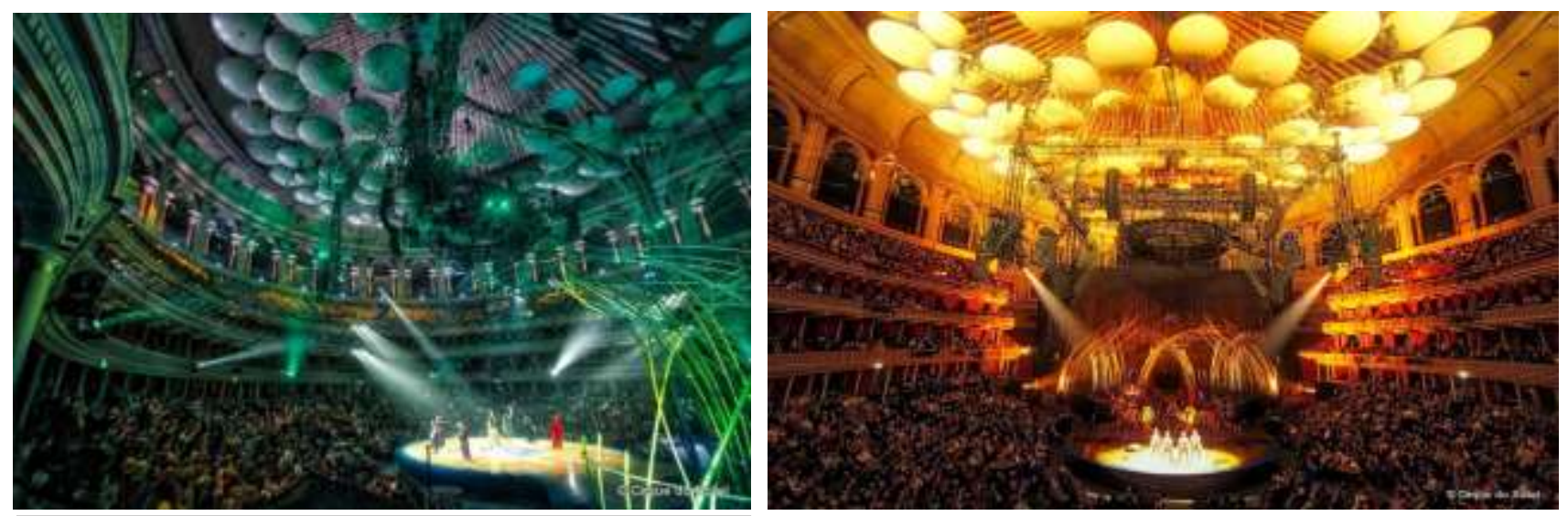

The fully integrated hall can be dismantled and reinstalled anywhere, the existing structure carrying the design is independent because the terraces did not have the required capacity to support the new roof so a separate structure had to be built, and the base of the structure consists of large concrete blocks above the ground. Column heights vary between 26 feet and 36 feet in collaboration with show designers. Elements are built that meet the required capacities and all safety standards for this type of equipment.

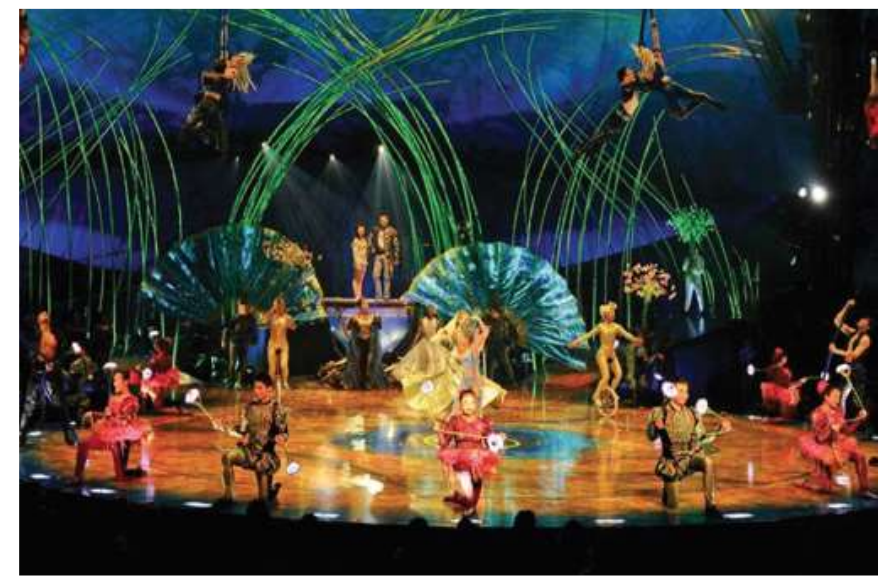

\section{Theatrical performance of Cirque de Soleil (TOTEM):}


TOTEM theatrical performance talks about the organic world, swamps surrounded by reeds near an island, on which images are projected, it was designed by Carl Fillion, and the design is composed of curves and non-linear shapes to reflect the natural world, The trampoline is installed

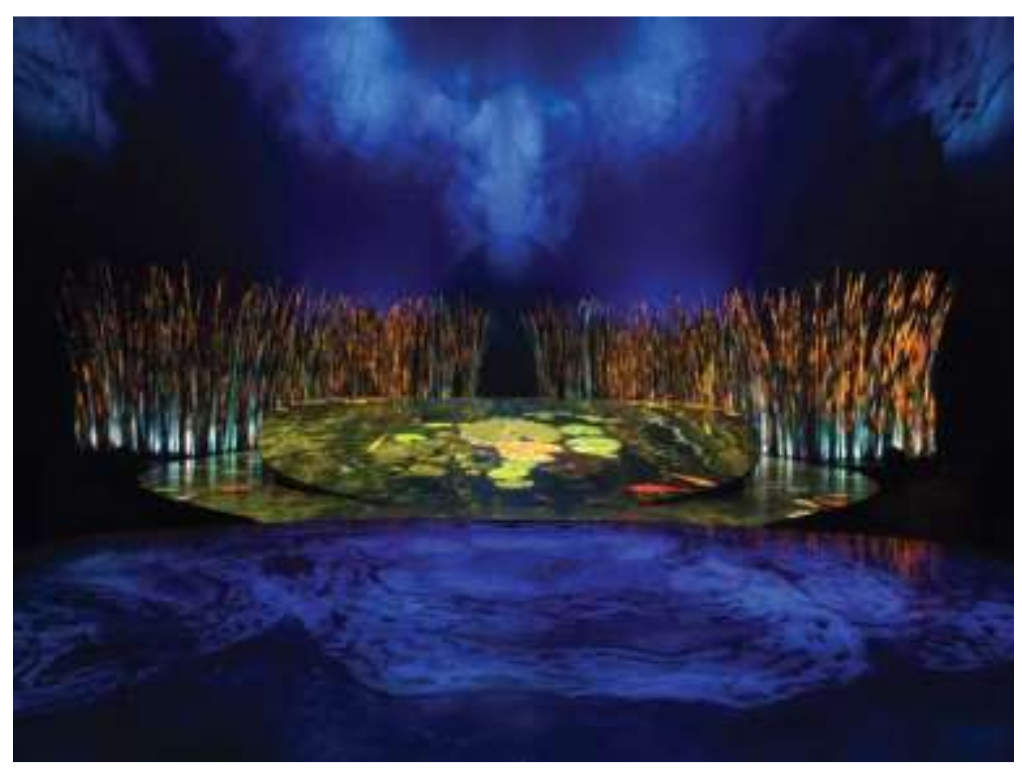
under the floor covering, the huge tortoiseshell was used as a decorative element. The skeleton is raised to the top of the tent or opened at an angle like an enormous shell which was disassembled for transport, A variety of motion pictures projected "Scorpion Bridge" that serves as a moving platform that links the design to the center of the stage Variable geometry features adaptable to each theatrical scene using eight hydraulic cylinders that allow the tail to rise,

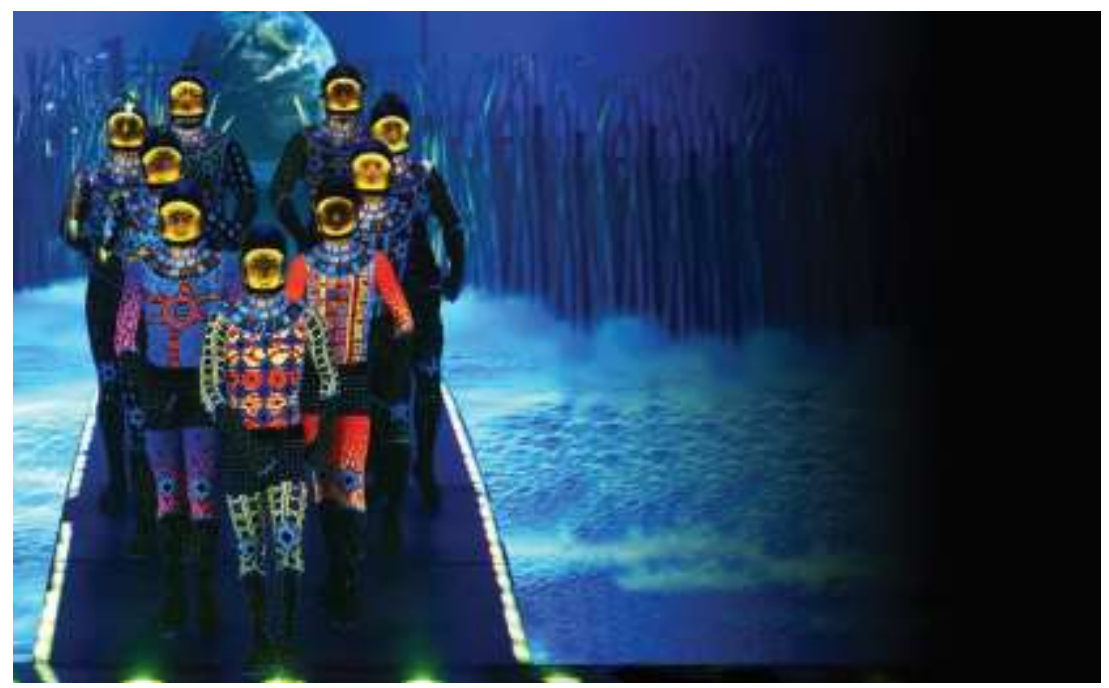

descend, extend and retract on itself like a scorpion's tail during the show, The bridge is monitored by the operator using four infrared cameras. The large oval frame on the stage represents the skeleton covered with a cloth printed with the signs of chance. 


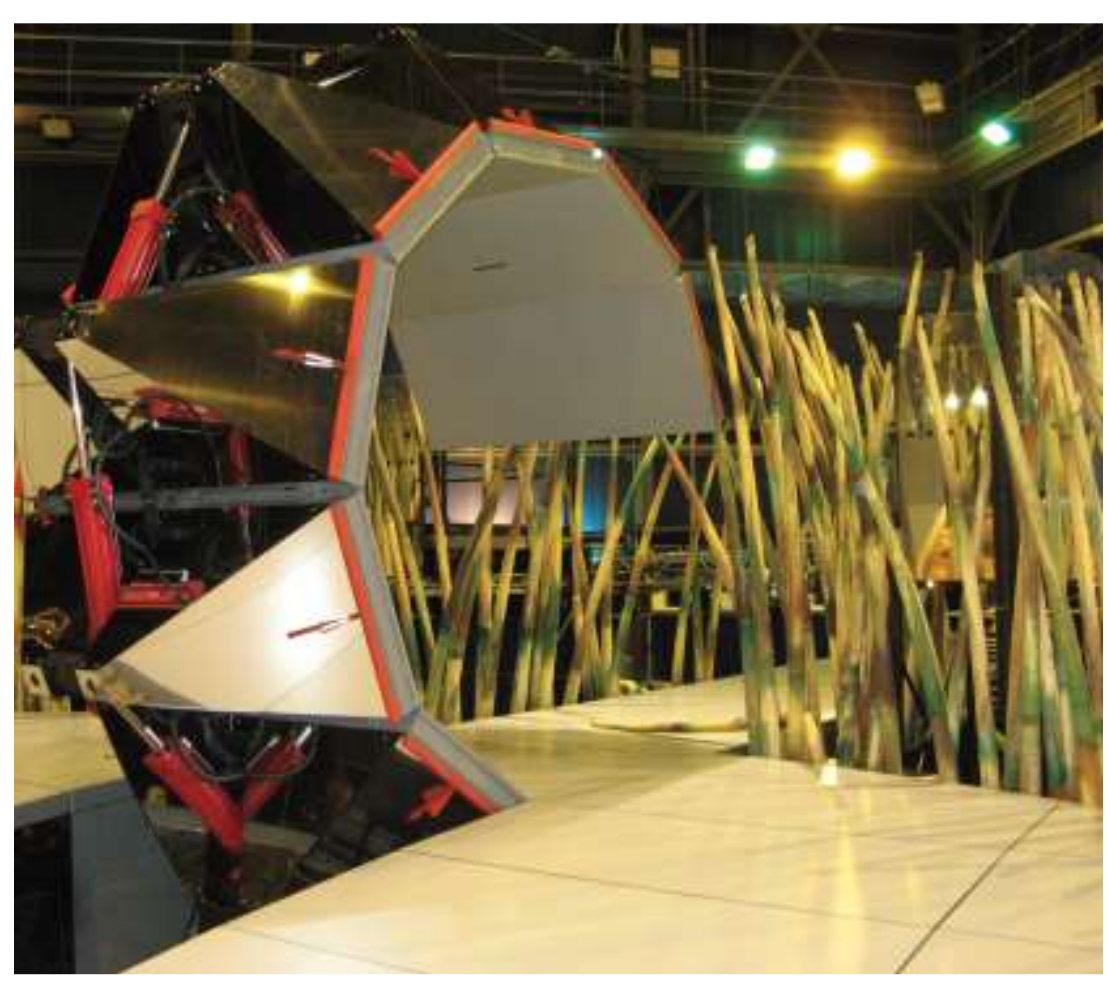

The bridge of the scorpion was based on the principle that it is retractable with eight powerful oil hydraulic motors that allow it to rise, descend, extend, retract and roll on itself like the tail of the scorpion. Its reflective surfaces that shine like mirrors are made of stainless steel plates.
In a multi-transformed organic world, Designer Carl Fillion has created curves and non-linear shapes to contemplate the natural world. as projecting surfaces. Through the magic of animation, it turns into a virtual swamp, a river source, a lake, an ocean, a volcanic island, a pond, and a starry sky. The boat then rises to become a plane in mid-air and the boat is made of steel,

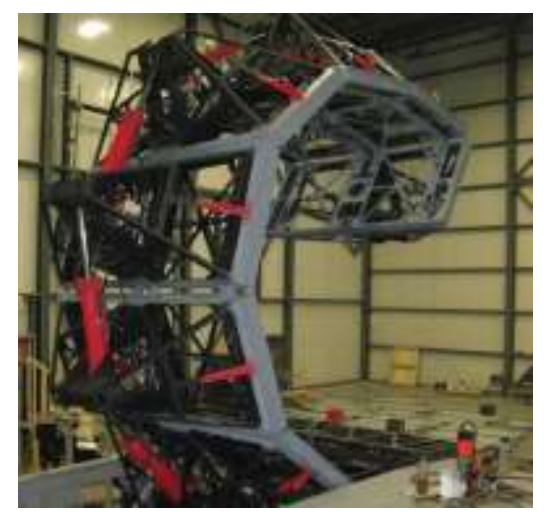

\section{The "O" theater:}

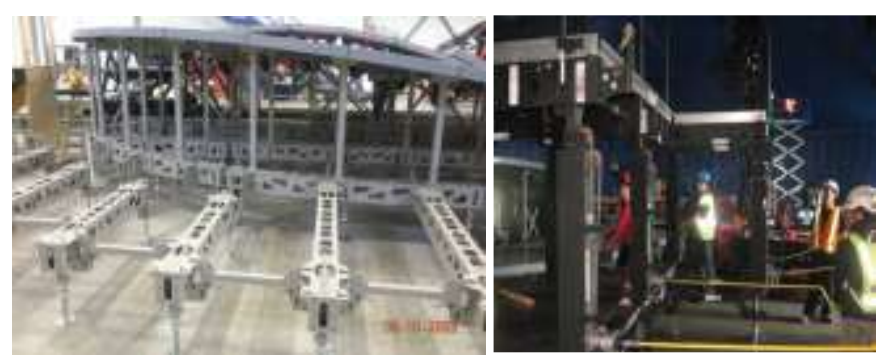




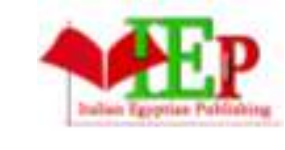

ISSN: $2735-4342$
INTERNATIONAL JOURNAL OF

MULTIDISCIPLINARY STUDIES IN ART AND

TECHNOLOGY

VOLUME 2, ISSUE 2, 2019, 29-47.

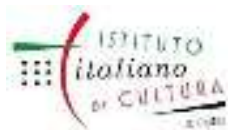

www.egyptfuture.org/ojs/

Theater "O" was built with a 1.5 million gallon pool 17 feet deep below the rest of the stage. The stage and massive water tank were specially designed for the Cirque de Soleil group, the show features synchronized swimming, snorkeling, acrobatics, and aerobics, all over 1.5 million gallons,

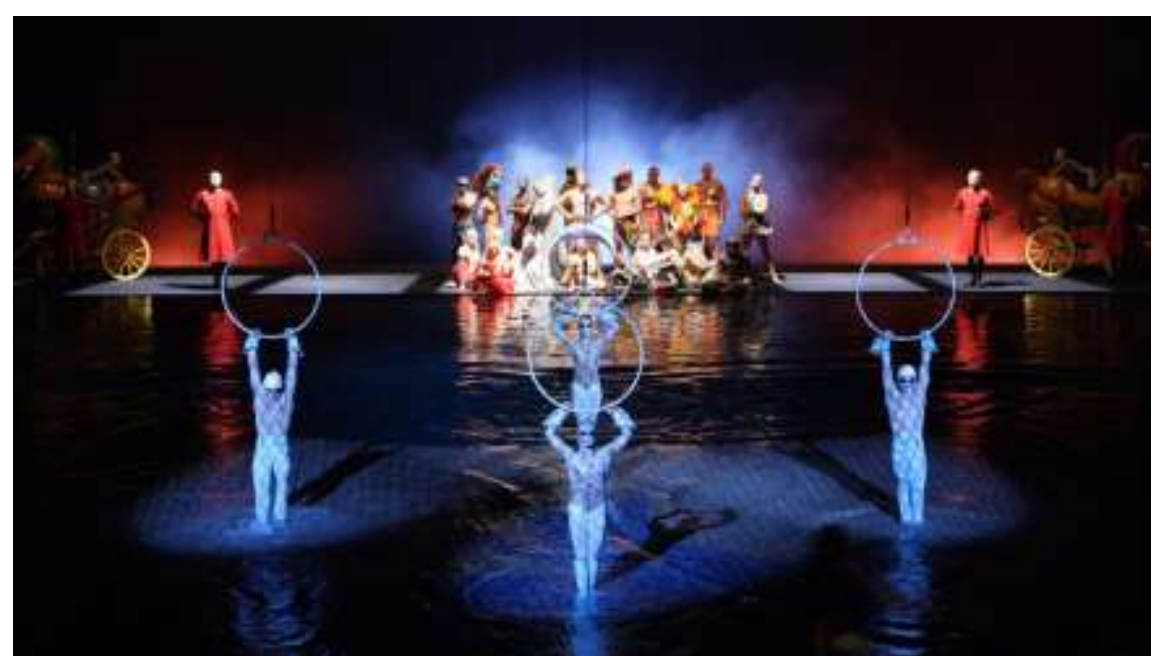

two of these divers wear full face masks during the performance, the show was able to create a very unique scenography. The stage, which measures 53 feet by 90 feet, was divided into four parts, controlled by advanced hydraulic lifts. Seven elevators can raise the stage from the pool floor, 17 feet, to 18 inches above water level.
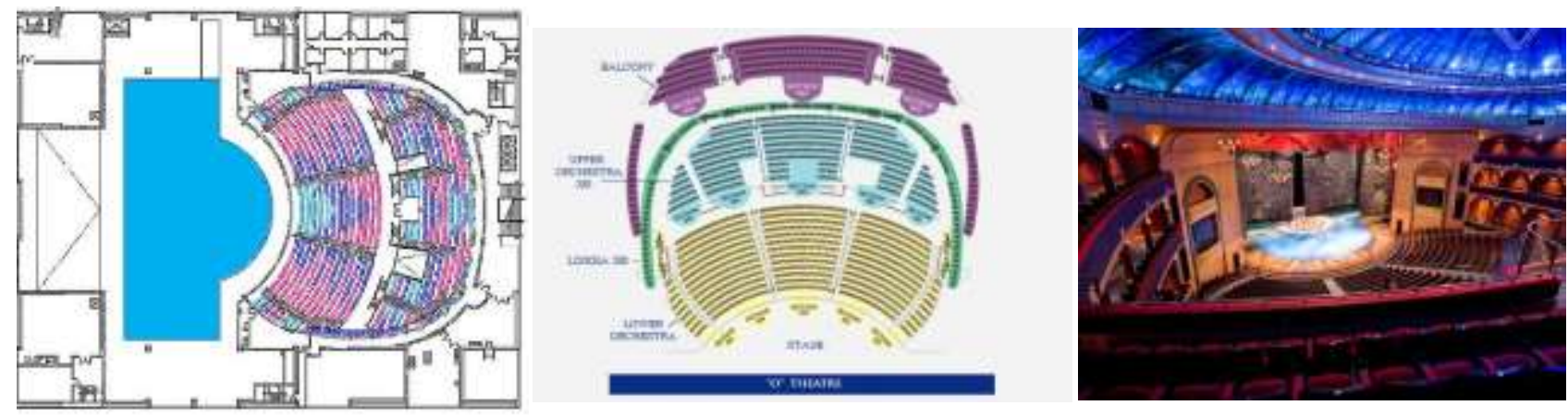

The swimming pool is like a reserve with a garden where the sun shines through the leaves of the forest and produces transparent colors of stained glass. Theatrical performances that were held on a water-filled theater of the Cirque de Soleil troupe, the theater has a capacity of 1,800 seats, in the style of the European Opera House, which dates back to the fourteenth century.

The ceiling consists of a galvanized metal mesh frame to allow the use of an infinite range of light effects and a lot of different colored lights to illuminate the stage to achieve the desired atmosphere. The transparent appearance is achieved through two layers of galvanized metal mesh illuminated from the back with light beams of multiple colors and intensity, and the result is a dynamic flash above the audience, and at the front of the stage, there is an aluminum frame from which hangs a chandelier with an independent moving system to serve the theatrical performance presented. In addition to a hoisting winch to move the performer up and down in conjunction with raising and lowering the chandelier. 


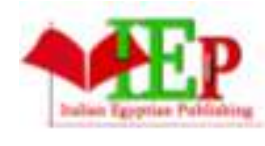

ISSN: $2735-4342$
INTERNATIONAL JOURNAL OF

MULTIDISCIPLINARY STUDIES IN ART AND

TECHNOLOGY

VOLUME 2, ISSUE 2, 2019, 29-47.

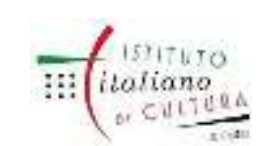

www.egyptfuture.org/ojs/

The theater contains a complex system of struts, walkways, and two winches to control the scenes, which consists of walkways, paths, platforms, the two winches are moving according to the desired function up and down in addition to the central rotating wheel in the ceiling to move the scenes up and down, one of the scenes consists of horses The four are made of fiberglass, run on battery power, and are equipped with propellers. The horses are controlled by two cranes. The mirror rises from the water on the stage. It must be able to move, including a 90-degree rotation around the axis, before rising vertically into a one-meter hole in the ceiling.

A botanical, root-like swamp, maze of scenes in the theatrical performance serves as a backdrop to many of the show's scenes, this canopy is made of vapor-resistant, hard plastic material through thermoforming, a process in which Lexan is poured into a 45 length mold Feet by $60 \mathrm{ft}$ and left to solidify, paint is applied to create a visual contrast with the darkened area, and white nylon curtains have been added to look like sails to add an air of glamor especially in rainy and foggy scenes, The swimming area is 25 feet deep and 150 feet long from right to left 100 feet from the top floor to the bottom under this deck A series of specially built hydraulic lifts Seven of these lifts can rise from 17 feet 3 inches below water level to 18 inches Above, moving separately or together Each elevator is operated by three hydraulic capsules, they use Plant-based, biodegradable hydraulic oils in these lifts and the floor is fitted with a flexible material like rubber (fiberglass with sports mat with PVC) in a series of 8-foot panels. Each panel has an additional 5,000 holes to allow water to pass through while raising or lowering, but elevators are only part of the innovation, Lots of the problems with the show were caused by the water itself, The unwanted noise of the waves falling on the sides of the pool is absorbed by a series of different-sized pebbles scattered around the pool, These rocks, used with a special $3 \mathrm{M}$ mat called Nomad, help in absorbing waves and noise, in addition to using bromine in the water to reduce the smell of chlorine as The holes allow bubbles to form hide any underwater activity. Performers need to stay underwater for up to 90 seconds at a time. Divers allow performers to breathe underwater during the performance, The water temperature is maintained almost constant, to maintain a constant temperature in the audience seating area a Special ventilation system is used under the seats and around the acting area while the lattice ceiling acts as a chimney and allows warm air to escape from the auditorium, Soft gobos have been added on the stage floor and clearer images of intertwining foliage and branches are placed on top of the gobo A more abstract rose window that looks like stained glass Cirque $\mathrm{du}$ Soleil has created custom shells using high-temperature citrus-colored paint on Vycor glass added to projected gobos On the stage and proscenium to add more illusion to the lighting. 


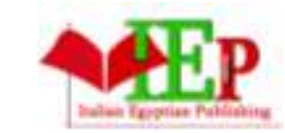

ISSN: $2735-4342$

\section{Recycled theatres:}

The first model is a quick-build, low-cost, demountable theater made of recycled materials, located in Britain, using unconventional building techniques and has been produced almost entirely from reusable materials, these materials are scaffolding, bamboo, and bales of paper from Recycling processes and some secondary materials such as cables, polycarbonate, and one piece of custommade steel structure. "Soundproof" This is the main challenge for light and demountable buildings, the theater takes on a circular shape with 135 seats, which are usually surrounded by fabrics and there is no barrier to the outside, these buildings are difficult to use from a scenographic point of view, as they lack solid surfaces, bridges, etc. It is based on a scaffolding frame that also serves as a frame for easy wall erection and dismantling. There are four doors - two for the audience, two for the performers, The soundproofed roof is made of a lightweight material which poses more of a challenge than the walls, and the demountable structures usually fold into a box-like shape often, while the structure comes in a shape (like a circus tent).
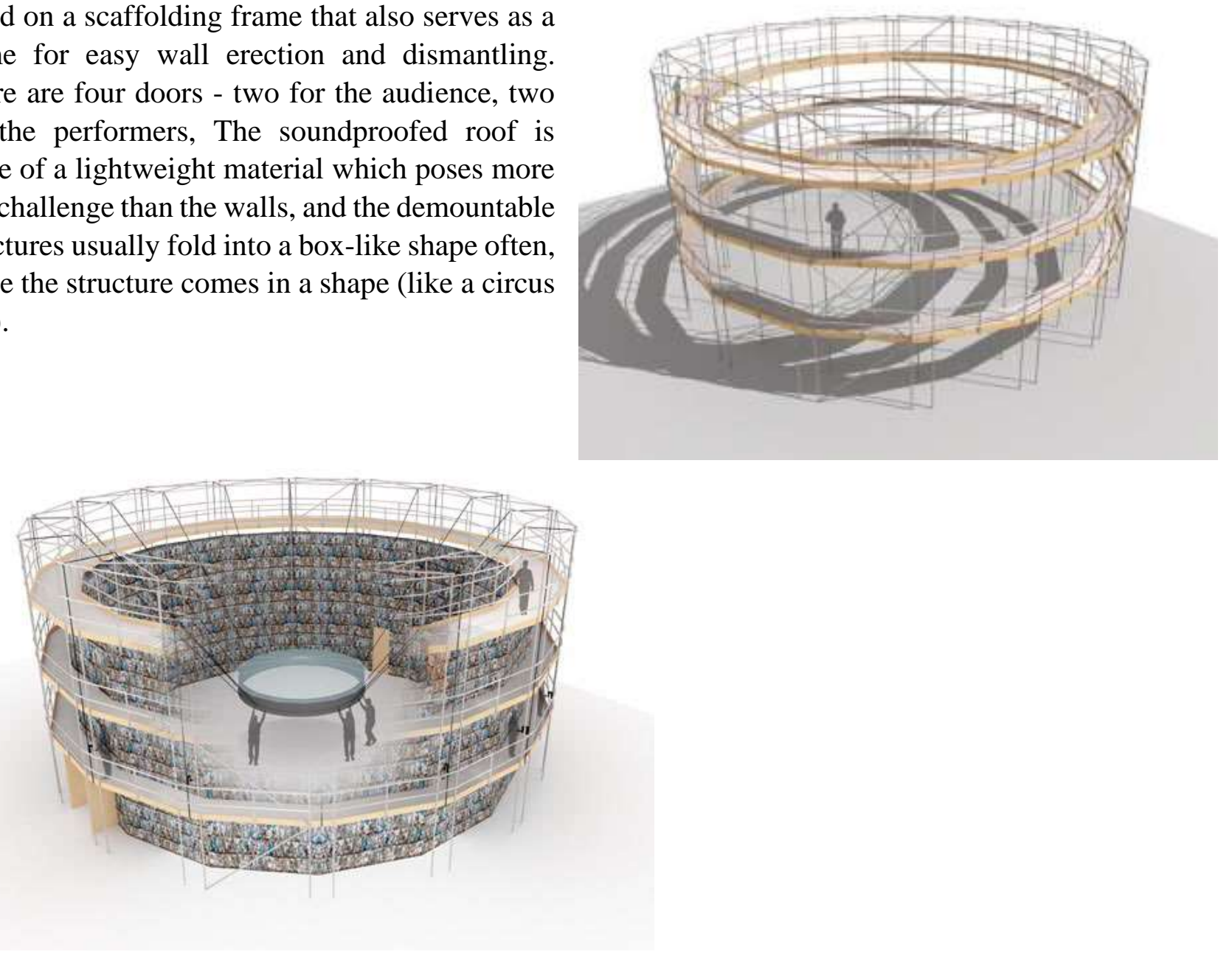


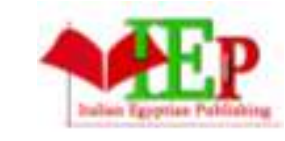

ISSN: $2735-4342$
INTERNATIONAL JOURNAL OF

MULTIDISCIPLINARY STUDIES IN ART AND

TECHNOLOGY

VOLUME 2, ISSUE 2, 2019, 29-47.

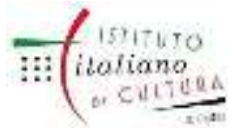

www.egyptfuture.org/ojs/

Bamboo is used on the surrounding walls as a structural material. The exterior of the double stage consists of a recycled circus tent-like material. They are usually disposed of after three years when they lose their tensile strength, while the roof is covered with a layer of bags filled with shredded paper (as for thermal and acoustic insulation), and then it is covered with another circus tent-type film as well. The ceiling consists of a main structural ring with a circular serrated bracket, as the dome is made of polycarbonate, which has a weatherproof property and allows natural light to pass through.
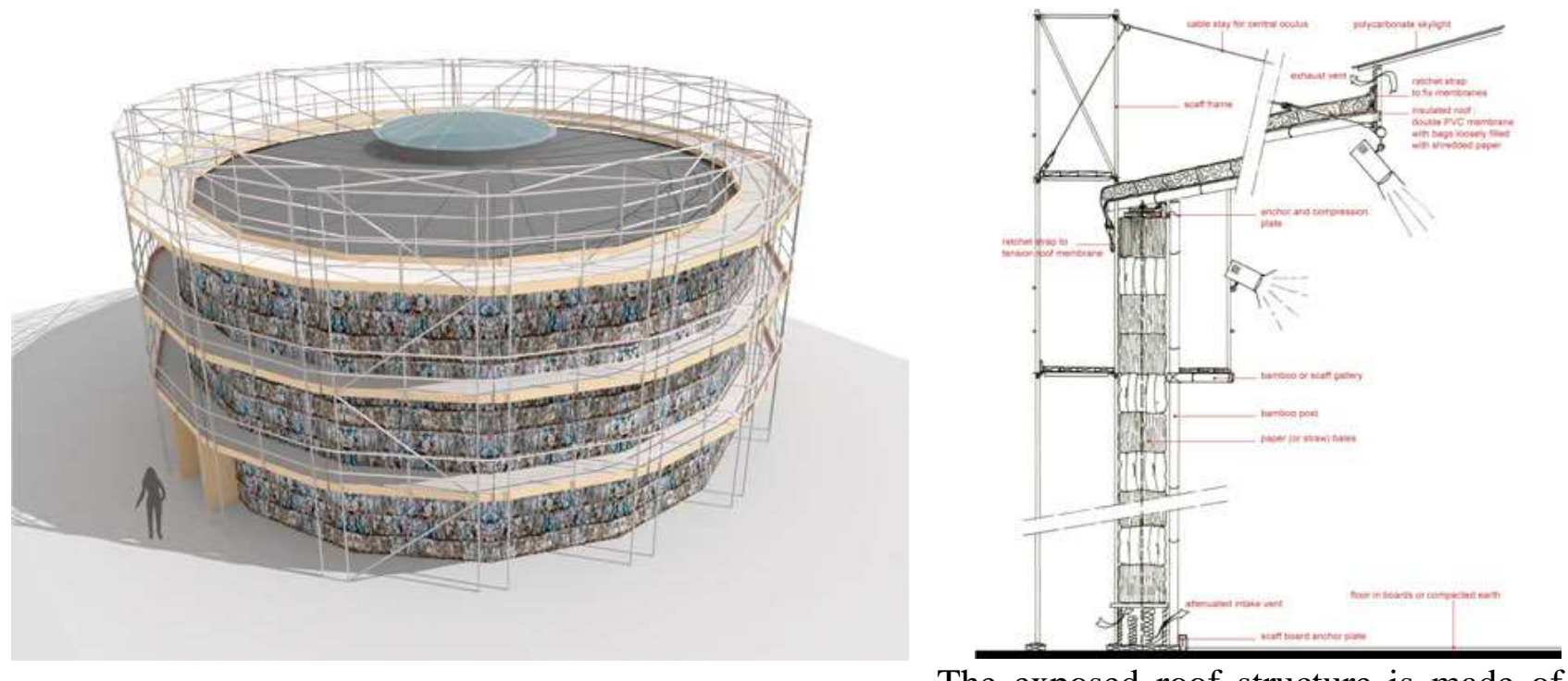

bamboo to give a warm feeling, the walls are made of large shaped corrugated board with flame retardant treatment and the seats are either paper or straw bales covered with sheepskin. $5 \mathrm{~m}$ high cantilevered scaffolding covers the entire area and the stage floor is made of scaffolding boards that are held together in a multi-layer system, with a final layer of $8 \mathrm{~mm}$ tin plates on top of tennis balls with space for cables.

The second model was Mazas, a self-financing theatre.

It is located 150 meters from the riverfront in the center of Paris next to the Bassin de l'Arsenal one of the most prestigious sites that Paris has to offer. Built-in 2017, Suitable for simple theater groups, the entire building is designed with a wooden structure and prefabricated components. In addition to the inherent sustainability benefits of wood, the building materials allow for lightweight, as a stage early and in the evening a concert. 


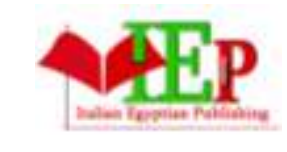

\section{INTERNATIONAL JOURNAL OF \\ MULTIDISCIPLINARY STUDIES IN ART AND \\ TECHNOLOGY}

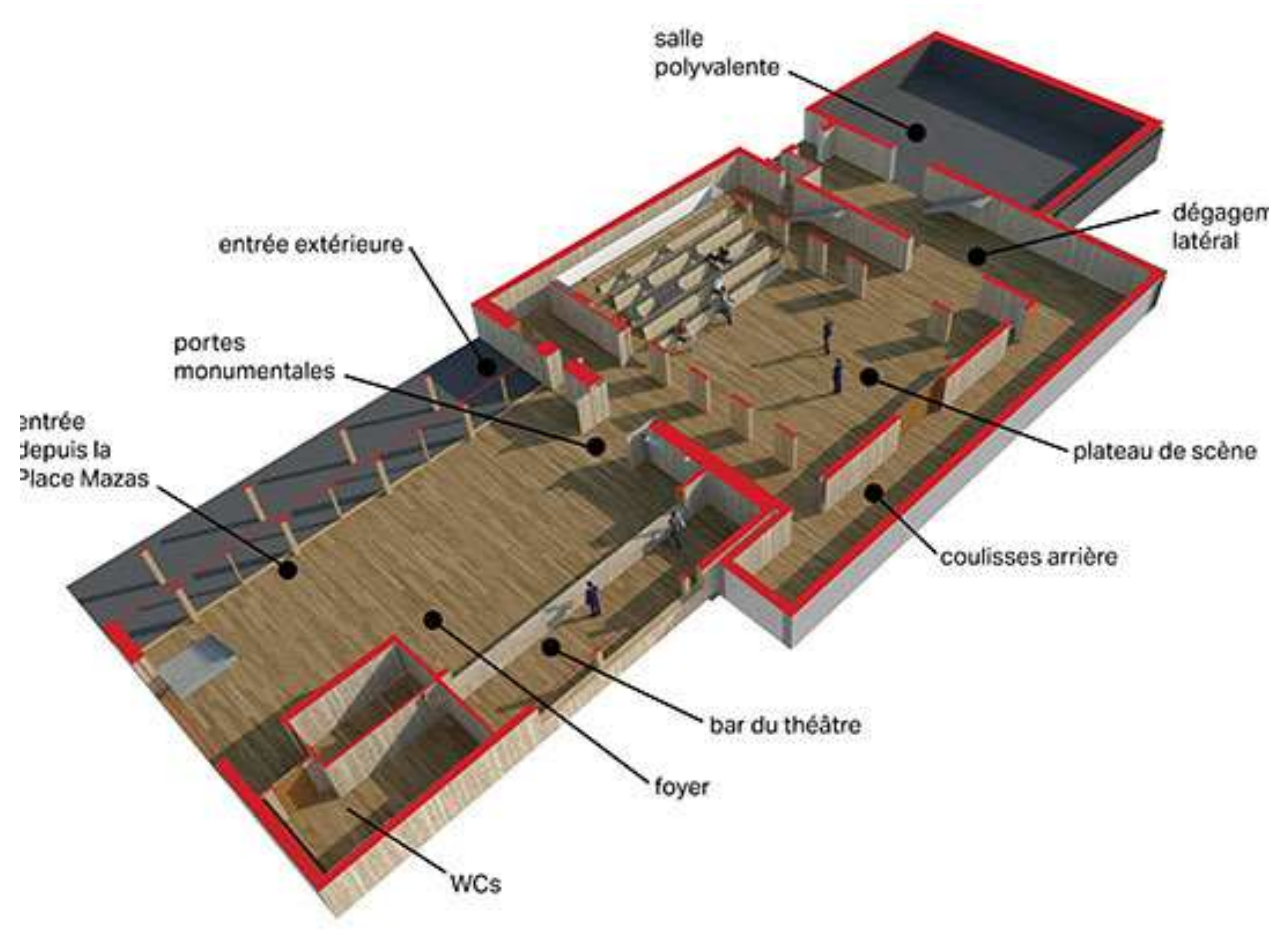

Or a DJ set, drawing a mixed audience into an art form the foyer was designed - with doubleheight doors for the stage as potentially an extension of the stage. 


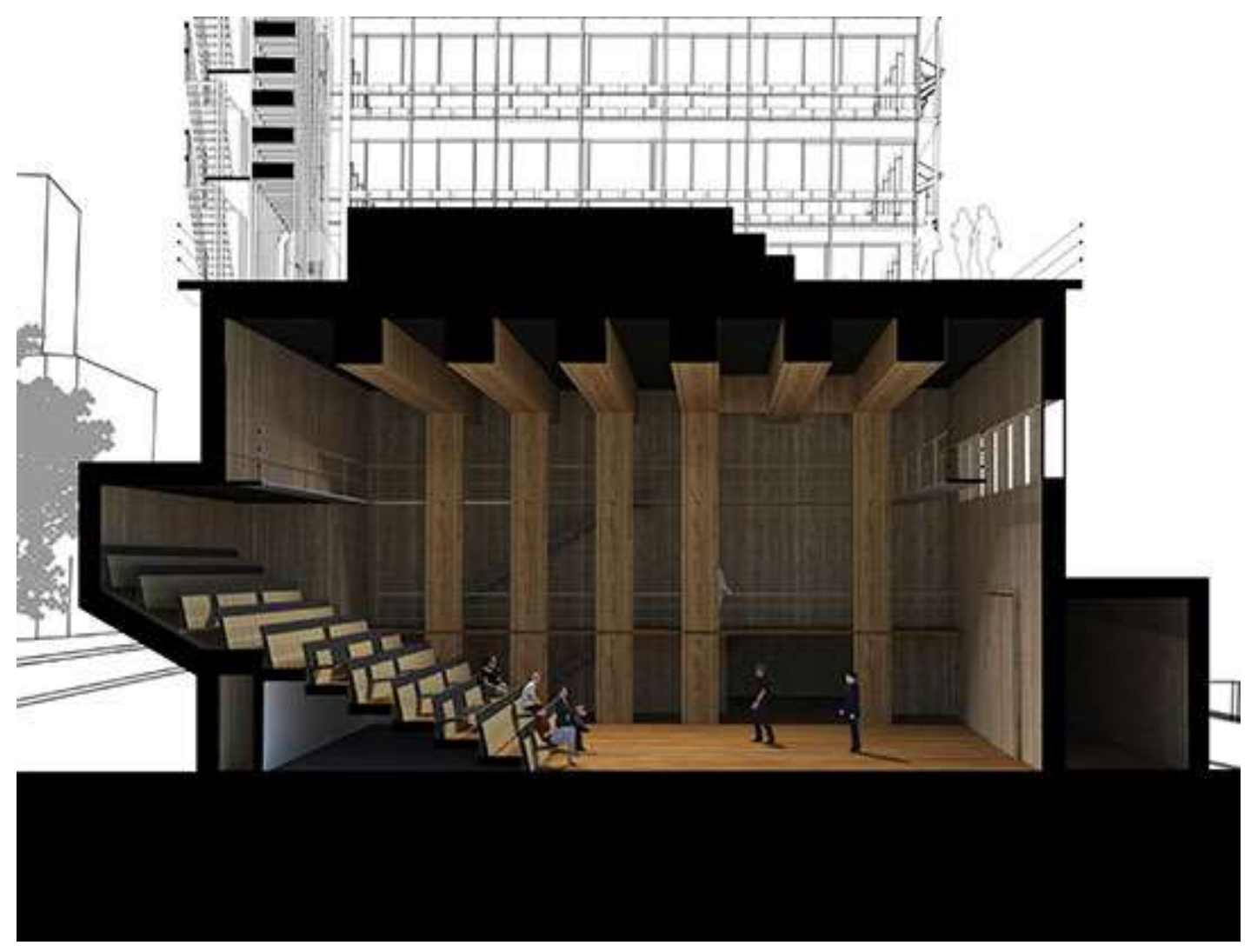

\section{Conclusion:}

From all of the Previous, we saw that the shows are colorful and contain a lot of light projections and technological capabilities that aim to create a visual experience to attract viewers by exploiting material technology to serve the design, and the exploitation of raw materials was in two ways by using raw materials as they are like bamboo, feathers, Cloth, nets, wood, rubber, and exploiting them by combining the kinetic mechanism of the elements and advanced technological techniques. Way of design, some designs have the ability to give a sense of kinetic dynamism (even if it is static) through the design that works within one system that is sensitive to movement, acoustics, and lighting systems, making them effective elements. Its shape is from nature or depending on nature by two aspects. 


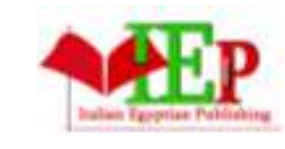

ISSN: 2735-4342
INTERNATIONAL JOURNAL OF

MULTIDISCIPLINARY STUDIES IN ART AND

TECHNOLOGY

VOLUME 2, ISSUE 2, 2019, 29-47.

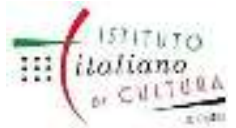

www.egyptfuture.org/ojs/

\section{Results:}

- materials can convey the kinetic feeling of the audience and attract attention through their movement and change their shape, including the required role in regulating the interconnection between the design elements to emphasize the aesthetic values of the moving elements by creating changing shapes characterized by their movement flexibility, which has always been fixed.

- Changing the surrounding conditions of some materials converts them from one substance to another substance that has other properties.

\section{$\underline{\text { Recommendations: }}$}

- It is necessary to try to create scenographic elements capable of forming and changing on their own according to the surrounding environment.

- Attempting to create scenographic elements capable of movement, interaction, and adaptation with weather conditions, with the psychological state, with the topography of the place, or even creating a scenography capable of growing and adapting to everything that surrounds it by balancing between the natural resources of the environment and our ability to exploit them for our benefit and Reducing the negative effects generated by our use of it.

- More studies should be conducted to develop the properties of materials and explore their capabilities and advantages that can be exploited on the one hand and the other hand reducing environmental damage by conducting an integrated experiment with components and reducing waste that accumulates without treatment.

\section{We must study:}

Taking advantage of the movements of atoms and relying on the crystal structure of the elements and trying to reshape it to have new properties that did not exist before.

- Benefiting from the technology of mechanical properties of materials by giving materials properties related to the weights of materials that did not exist before.

- Raw materials and their effect on natural factors (rain - natural light - air - steam ....) and industrial factors (industrial lighting and its impact on the properties of materials and their transformation - heat emitted from lighting units ...).

- Mixing some raw materials and elements to obtain new materials that bear the characteristics of their components and can be reused again. 


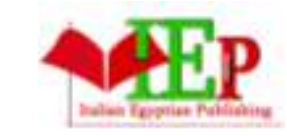

ISSN: $2735-4342$

\section{INTERNATIONAL JOURNAL OF \\ MULTIDISCIPLINARY STUDIES IN ART AND \\ TECHNOLOGY}

VOLUME 2, ISSUE 2, 2019, 29-47.

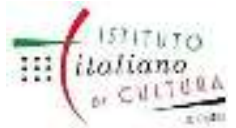

www.egyptfuture.org/ojs/

- Ensure the coefficient of expansion and contraction of each material and the ability to use its properties of expansion and contraction to serve the design.

\section{$\underline{\text { References }}$}

- $\quad$ http://creativecommons.org/licenses

- http://www.forbes.com/sites/michaelvenables/2013/08/30/technology-behind-the-magical-universe-ofcirque-du-soleil-part-one/\#60dd54c2166b

- http://www.wired.com/2010/02/cirque-du-soleils-sophisticated-ka-evolves-with-new-tech/

- http://sw14group.com/2010/02/the-technology-of-cirque

- $\quad$ http://www.stagetech.com/articles/scenic-automation-control-ka

- http://www.freelancer-frank.com

- http://www.generikvapeur.com/html/documents/doc.php3

- http://archives.lefourneau.com/jeudis/12/jeudi23aout.htm

- http://vancouverscape.com/a-behind-the-scenes-look-at-cirque-du-soleils-totem-in-vancouver/

- http://sefabrication.com/en/capabilities/stage-structure/

- http://www.koreaherald.com

- https://www.afoolintheforest.com/2009/02/ringolevio.html

- http://www.wagneropera.net/articles/articles-los-angeles-rheingold-2009.htm

- $\quad$ https://www.azcentral.com/story/entertainment/music/2018/06/22/kenny-chesney-concert-phoenix-chasefield-behind-scenes-what-know/720133002/

- $\quad$ https://www.cnet.com/pictures/tech-behind-cirque-du-soleil-o-las-vegas-ces-2017/19/

- $\quad$ https://www.richasi.com/Cirque/Luzia/didyaknow.htm

- http://www.marquardtplus.com

- http://www.cirquefascination.com/?p=5791

- $\quad$ https://www.live-production.tv/news/shows/l-acoustics-flies-high-cirque-du-soleil\%E2\%80\%99samaluna.html

- https://www.radiobremen.de/bremenzwei/aktuell/erinnerungen-an-wilfried-minks100.html

- https://www.csmonitor.com/World/Olympics/2014/0207/Sochi-opening-ceremony-glimpse-of-NewRussia-echo-of-the-old

- https://tvline.com/gallery/winter-olympics-2014-the-best-and-worst-moments-from-the-sochi-openingceremonies/sochi-opening-hammer-sickle/

- https://articles.triplewidemedia.com/the-technology-behind-the-sochi-olympics-opening-ceremony

\section{Scientific research:}

- International Symposium on "Novel structural skins - Improving sustainability and efficiency through new structural textile materials and designs, www.sciencedirect.com, Procedia Engineering 155 ( 2016 ) 47 60, ELSEVIER.

\section{Articles:}

Cirque Du Soleil's Delirium Ditches the Big Top as It Hops Arenas across North America By Mark A. Newman, March 2006 L I V E D E S I G N

\section{The documents:}




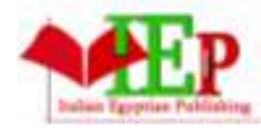

ISSN: $2735-4342$
INTERNATIONAL JOURNAL OF

MULTIDISCIPLINARY STUDIES IN ART AND

TECHNOLOGY

VOLUME 2, ISSUE 2, 2019, 29-47.

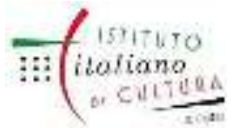

www.egyptfuture.org/ojs/

Cirque du Soleil, Sun Logo, Alegría, Dralion, Quidam, Varekai, Corteo, KOOZA, OVO, TOTEM, Amaluna, Kurios, Mystère, "O”, Zumanity - the Sensual Side of Cirque du Soleil, La Nouba, KÀ, Zarkana, are trademarks

Owned by Cirque du Soleil and used under license. The trademark LOVE is owned by The Cirque Apple Creation Partnership and used under license. The Beatles is a trademark owned by Apple Corps Limited. TheTrademarks CRISS ANGEL and Believe are owned by Criss Angel and used under license. Michael Jackson THE IMMORTAL World Tour is a trademark owned by Cirque Jackson I.P., LLC. Trademarks used under License. The Michael Jackson name, image, likeness and associated trademarks and logos are owned by Triumph International, Inc. and used under license. () 2010 Cirque Jackson I.P., LLC.

Received: October 2019

Accepted: December 2019 